\title{
Using Medium-Cost Sensors to Estimate Air Quality in Remote Locations. Case Study of Niedzica, Southern Poland
}

\author{
Ewa Adamiec ${ }^{1}{ }^{\oplus}$, Jacek Dajda ${ }^{2}\left(\mathbb{D}\right.$, Agnieszka Gruszecka-Kosowska ${ }^{1}{ }^{\oplus}$, \\ Edeltrauda Helios-Rybicka ${ }^{1}{ }^{(0}$, Marek Kisiel-Dorohinicki ${ }^{2}{ }^{\circledR}$, Radosław Klimek ${ }^{3, *}{ }^{\circledR}$, \\ Dariusz Pałka ${ }^{3}$ (D) and Jarosław Wąs ${ }^{3, *(D)}$ \\ 1 Department of Environmental Protection, AGH University of Science and Technology, \\ Al. Mickiewicza 30, 30-059 Krakow, Poland \\ 2 Department of Computer Science, AGH University of Science and Technology, \\ Al. Mickiewicza 30, 30-059 Krakow, Poland \\ 3 Department of Applied Computer Science, AGH University of Science and Technology, \\ Al. Mickiewicza 30, 30-059 Krakow, Poland \\ * Correspondence: rklimek@agh.edu.pl (R.K.); jarek@agh.edu.pl (J.W.)
}

Received: 31 May 2019; Accepted: 10 July 2019; Published: 13 July 2019

\begin{abstract}
The aim of this study was to assess air quality by using medium-cost sensors in recreational areas that are not covered by permanent monitoring. Concentrations of air pollutants PM2.5, PM10, $\mathrm{PM} 1, \mathrm{CO}, \mathrm{O}_{3}, \mathrm{NO}_{2}$ in the Niedzica recreational area in southern Poland were obtained. The research revealed that in cold weather, particulate matter concentrations significantly exceeded acceptable levels determined for PM2.5 and PM10. The most important factor that affects air quality within the studied area seems to be the combustion of poor quality fuels for heating purposes. The information obtained by the research presented could be a useful tool for local authorities to make environmental decisions, based on the potential health impacts of poor air quality levels on the population.
\end{abstract}

Keywords: air quality; medium-cost sensor; CAQI index; air quality assessment tool

\section{Introduction}

Air pollution is an international problem that contributes to a variety of environmental and health issues, leading to serious economic losses. These problems will become much more pressing in the forthcoming decades if appropriate measures are not undertaken. Despite reduced emissions, large tourist and residential areas are still affected by air pollution. Since the early eighties, air pollution has been significantly reduced, particularly $\mathrm{SO}_{2}$ levels, but $\mathrm{NO}_{x}$ concentration has remained high and $\mathrm{O}_{3}$ concentration has increased significantly in Europe [1].

The Sejm, the Polish national parliament, adopted a law in June 2019 to accelerate the process of eliminating threats caused by air pollution, including PM10 and PM2.5 suspended dust and benzopyrene. These activities are aimed at meeting EU requirements on ambient air quality and cleaner air for Europe; see directive [2]. Significant progress has been made in recent years to reduce pollution emissions by so-called large and industrial objects, however, smaller and local emission sources remain a problem; see [3].

Air pollution has resulted in increased legislative measures and significant technological improvements, thus contributing to the reduction of emissions from industry. Public awareness of air pollution and the need for effective pollution control strategies have led to the reduction of emissions from industry, although household emissions remain high and uncontrollable. At the same time, research projects devoted to lowering emissions have begun to appear, but no 
efficient legislative measures or technological improvements aimed at reducing household emissions have been implemented.

The most recent Global Burden of Disease (GBD) study estimates that in 2013, air pollutionboth indoor and outdoor - was the cause of 5.5 million premature deaths globally, and the latest GBD predicts up, to 6-9 million annually by 2060 [1], including around 400,000 in Europe [4]. These deaths are related to systemic oxidative stress, respiratory and cardiovascular dysfunctions, and diseases such as atherosclerosis, altered cardiac autonomic function, ischaemic cardiovascular disease, haemorrhagic stroke, and pulmonary inflammation [5-8], as well as cancers, in particular lung cancer [9-11].

Increasing economic activity and energy demand will lead to a significant increase in global emissions from air pollutants [1]. According to [1], rising emissions of air pollutants are projected to lead to higher concentrations of particulate matter (PM2.5) and ground level ozone. In particular, emissions of $\mathrm{NO}_{x}$ are projected to increase sharply. Emissions of $\mathrm{SO}_{2}$ are projected to decrease initially, but will increase again after 2030. Air pollution can directly and indirectly affect health, while generating increased costs; see [12]. Further emission reduction measures should therefore be undertaken, particularly in tourist areas, which are commonly used for recreational purposes. Tourist areas are particularly valued if their natural conditions offer opportunities for outdoor activities. In the mountains, the area investigated by this study, outdoor activity is dominated by winter sports, so the highest volume of tourist traffic is expected in winter. Winter house heating in Poland is mainly provided by coal and wood, which are often burnt in inefficient heating furnaces, occasionally alongside household waste. Paying attention to the fact that tourists' ecological awareness of the impact of environmental pollution on human health is growing, knowledge of the air quality in tourist towns becomes crucial. The issues of long-term integrated regional prevention and control of air pollution have been emphasised on a political level. Further emission reduction measures should therefore be undertaken especially in tourist and residential areas, since long-term integrated prevention and control actions directed at air pollution have not yet been developed on regional levels. The test results obtained will allow exploration of the challenges that the system faces and allow continuous development of guidelines for an effective strategy in recreational areas such as Niedzica.

The closest air quality monitoring station running under the Polish National Monitoring Program, which analyses concentrations of particulate matter PM10, and benzo[a]pyrene (BaP), is located in Nowy Targ, a town about $5 \mathrm{~km}$ west of the nearest tourist town (Waksmund) and about $25 \mathrm{~km}$ west of the farthest tourist town (Czorsztyn) in the investigated area of the Niedzica recreational area. In the south and south-west direction, the second-closest air quality monitoring station of the Polish National Monitoring System is located in Zakopane, at a distance of $30 \mathrm{~km}$ from Waksmund, $40 \mathrm{~km}$ from Frydman, and $45 \mathrm{~km}$ from Niedzica (see: http://en.wikipedia.org/wiki/Niedzica). This air quality station analyses nitrogen dioxide $\left(\mathrm{NO}_{2}\right)$, nitrogen oxides $\left(\mathrm{NO}_{x}\right)$, nitrogen oxide $(\mathrm{NO})$, ozone $\left(\mathrm{O}_{3}\right)$, carbon monoxide $(\mathrm{CO})$, benzene $\left(\mathrm{C}_{6} \mathrm{H}_{6}\right)$, particulate matter PM10 and PM2.5, and benzo[a]pyrene (BaP) [13].

In the middle of 2019, three low-cost Airly sensors (see http://airly.eu)—quite popular in Poland at present-which analyse the concentration of particulate matter in ambient air, were placed in the investigated area, one in the area of Nowy Targ and two in the area of Szczawnica (see http:/ / airly.eu/map/pl/).

One can distinguish between different kinds of air pollution sensors. It should be emphasised that there is no single widely accepted definition of the price categorisation of air quality sensors: low cost, average cost, and medium cost. For example, according to the document of the European Commission [14], metal oxide sensors applied to measure $\mathrm{NO}_{2}, \mathrm{O}_{3}, \mathrm{CO}$ are classified as low-cost sensors (10-15 EUR/sensor), electrochemical sensors applied to measure $\mathrm{NO}_{2}, \mathrm{SO}_{2}, \mathrm{O}_{3}, \mathrm{NO}, \mathrm{CO}$ are classified as medium-cost sensors (50-100 EUR for a sensor), photo ionisation detectors applied to measure VOCs (volatile organic compounds) are classified as moderate class sensors (400 EUR for a sensor, up to 5000 EUR for the whole device), optical particulate counter applied to measure PM are classified as of moderate cost (300 EUR for a sensor, up to 2000 EUR for whole device), and optical 
sensors applied to measure $\mathrm{CO}$ and $\mathrm{CO}_{2}$ are classified as moderate cost (100-350 EUR for a sensor, up to 2000 EUR for the whole device). Simultaneously, the "Air Sensor Guidebook" of the United States Environmental Protection Agency [15] does not provide a direct price range for low-cost sensors, but does note that costs of "consumer-based" air quality sensors often range from 100 to 2500 USD. Taking different approaches into account, we propose classifying our sensors as medium-cost sensors.

Thus, in this research, medium-cost sensors are used in a tourist and residential area. Such sensors were used because, on the one hand, the local government does not have the budget for expensive stations, and on the other hand, they offer enough parameters to calculate the Common Air Quality Index (CAQI). Pollution investigation was carried out during the critical winter period (observable impact of heating on the level of contamination), after the introduction of sensors on the market. An important consideration is having the ability to move the sensors, while ensuring the continuous operation of the measurement system. This allows the sensors to operate in different locations, and offers the local authorities a chance to intervene when necessary.

Taking the above into consideration, the aim of the study was to verify the usefulness of medium-cost environmental stations used for complex air quality measurements (a few atmospheric air parameters at the same time) in real world conditions and to determine the air quality in 12 locations in the Niedzica recreational area-a popular tourist region in Southern Poland (the Karpaty Mountains).

\section{Related Works}

Liu et al. [16] compared the reliability of six PM sensors, consisting of five optical sensors and one mechanical PM sensor produced by Sharp, Shinyei, Samyoung, Oneair, TSI DustTrak, and Personal Dust Monitor (PDM). They confirmed that the final readouts of tested PM devices are linearly related to the concentration of the mass of particles when exposed to particles with a fixed size distribution and composition. They confirmed that low-cost sensors can be used; however, calibration procedures are required before application, using representative ambient particles, and under the steady-state particle mass concentration. Yang et al. [17] considered the evolutionary relationship between global urbanisation on Earth and PM2.5. They considered PM2.5 concentrations in the period between 1998 and 2015, as well as changes to the levels of urbanisation in East Asia, Southeast Asia, South Asia, and some African countries, finally identifying a positive correlation between PM2.5 and urbanisation. Wang et al. [18] analysed real transaction data from a leading online travel agency in China and compared it with the impact of the air quality on outbound tourism demand. They identified a delay effect of five days in the impact of the air quality on outbound tourism demand. They confirmed that the daily Air Quality Index (AQI) is correlated with tourism in particular regions of China and that it enforces the flow of tourist traffic to destinations with better air quality. Bełcik et al. [19] investigated cytotoxicity, genotoxicity, and mutagenicity conducted on PM2.5 collected over an entire year in the Wrocław agglomeration in Poland. They used the following tests: salmonella test for mutagenicity, comet assay for genotoxicity, and Pan I test for cytotoxicity. In their study, the authors pointed out the differences in cytotoxic, genotoxic, and mutagenic properties of particular seasons, as well as the volumes of pollution fractions of dust. They identified that the worst properties of dust particles were collected during winter and autumn. Dzikuć [20] analysed low-emission issues originating from heating private houses and from road transport. The author presented the different actions taken to reduce ground-level emissions in particular locations and then analysed their effectiveness, including, e.g., reducing the number of coal boilers or banning cars that do not comply with environmental standards. 


\section{Material and Methods}

\subsection{Study Area}

The research was conducted in 12 touristically attractive locations in Southern Poland, see Figure 1 and Table 1. Eleven of these were located in the recreational area of Niedzica. Nine measurement points were located in the vicinity of tourist destinations.

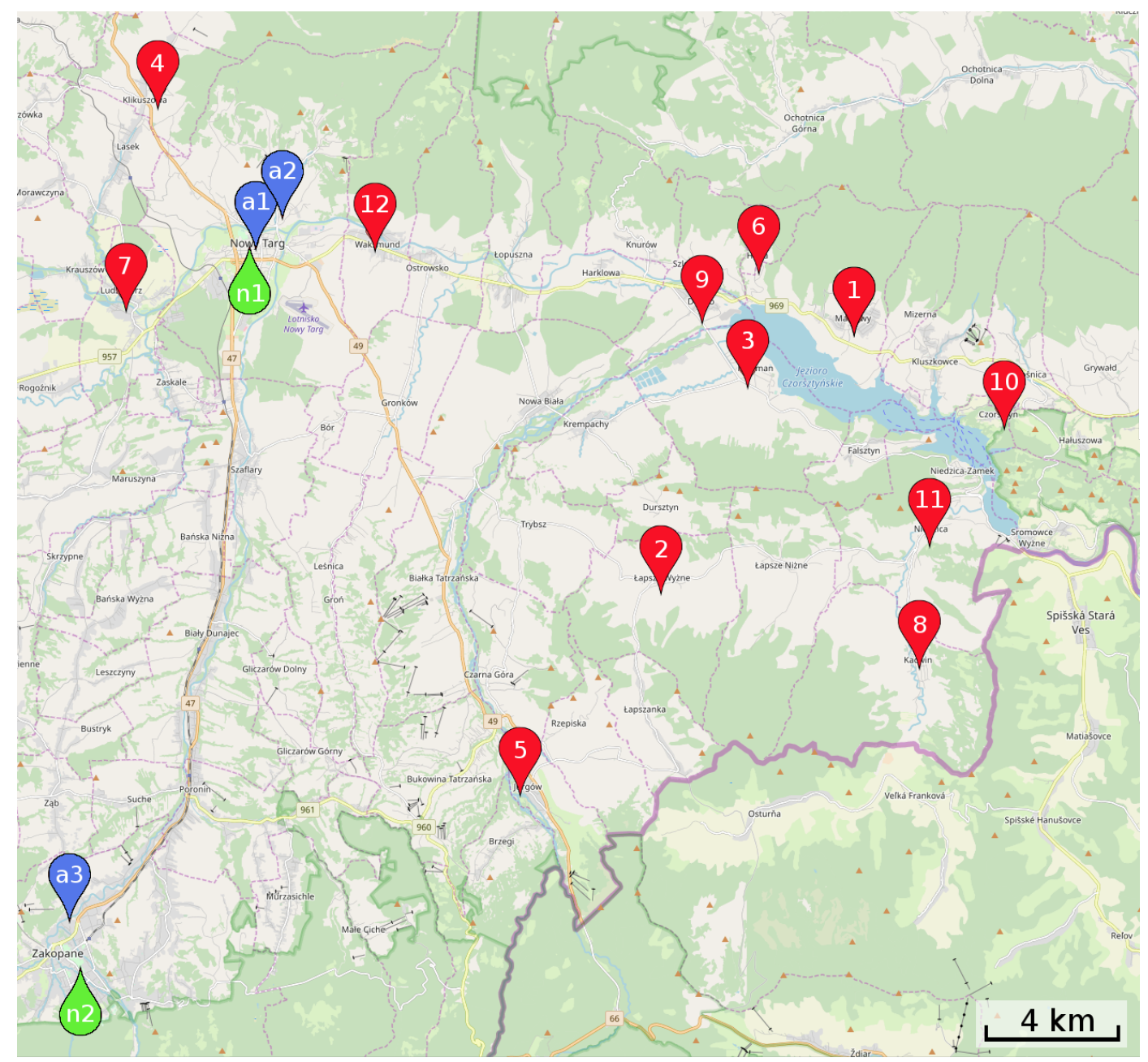

Figure 1. Air quality measurement locations. Markers: 1 -School in Maniowy, 2-School in Łapsze Wyżne, 3-School in Frydman, 4-School in Klikuszowa, 5-Jurgów, 6-Fire station in Huba, 7-School in Ludźmierz, 8-School in Kacwin, 9-School in Dębno, 10-Fire station in Czorsztyn, 11-School in Niedzica, 12-School in Waksmund. Green markers-Regional Monitoring System stations in Nowy Targ (n1) and Zakopane (n2). Blue markers (a1, a2, a3) - the Airly stations. The base map comes from OpenStreetMap. 
Table 1. Characteristics of air quality measurement points in the Niedzica recreational area.

\begin{tabular}{cccccc}
\hline \multirow{2}{*}{ Location } & \multirow{2}{*}{ Location Number } & \multirow{2}{*}{ Place } & \multicolumn{2}{c}{ Coordinates } & \multirow{2}{*}{ Date of Measurement } \\
\cline { 4 - 5 } & & & Latitude & Longitude & \\
\hline Maniowy & 1 & school & $49.46188^{\circ} \mathrm{N}$ & $20.26934^{\circ} \mathrm{E}$ & 18 December 2017-3 January 2018 \\
Łapsze Wyżne & 2 & school & $49.39477^{\circ} \mathrm{N}$ & $20.19147^{\circ} \mathrm{E}$ & 3 January 2018-8 January 2018 \\
Frydman & 3 & school & $49.44837^{\circ} \mathrm{N}$ & $20.22652^{\circ} \mathrm{E}$ & 8 January 2018-15 January 2018 \\
Klikuszowa & 4 & school & $49.52095^{\circ} \mathrm{N}$ & $19.99045^{\circ} \mathrm{E}$ & 15 January 2018-19 January 2018 \\
Jurgów & 5 & comparative area & $49.34218^{\circ} \mathrm{N}$ & $20.13555^{\circ} \mathrm{E}$ & 19 January 2018-22 January 2018 \\
Huba & 6 & fire station & $49.47947^{\circ} \mathrm{N}$ & $20.23062^{\circ} \mathrm{E}$ & 23 January 2018-28 January 2018 \\
Ludźmierz & 7 & school & $49.46872^{\circ} \mathrm{N}$ & $19.97737^{\circ} \mathrm{E}$ & 31 January 2018-5 February 2018 \\
Kacwin & 8 & school & $49.37533^{\circ} \mathrm{N}$ & $20.29423^{\circ} \mathrm{E}$ & 6 February 2018-12 February 2018 \\
Dẹbno & 9 & school & $49.46648^{\circ} \mathrm{N}$ & $20.20809^{\circ} \mathrm{E}$ & 12 February 2018-20 February 2018 \\
Czorsztyn & 10 & fire station & $49.43738^{\circ} \mathrm{N}$ & $20.32869^{\circ} \mathrm{E}$ & 20 February 2018-27 February 2018 \\
Niedzica & 11 & school & $49.40762^{\circ} \mathrm{N}$ & $20.29574^{\circ} \mathrm{E}$ & 27 February 2018-6 February 2018 \\
Waksmund & 12 & school & $49.48339^{\circ} \mathrm{N}$ & $20.07615^{\circ} \mathrm{E}$ & 6 March 2018-9 March 2018 \\
\hline
\end{tabular}

\subsection{Measurement Method}

Low-cost measurement stations generally only measure certain parameters, such as PM2.5 and PM10 dust, along with temperature and pressure. The application of medium-cost sensors makes it possible to additionally measure a number of other parameters, such as the concentration of various gases (carbon dioxide, nitrogen dioxide, ozone, and so on). Such parameters are required for CAQI calculations. This station uses an Alphasense (Alphasense, Sensor Technology House, United Kingdom, http:/ / www.alphasense.com) OPC-N2 sensor as a particle counter, which measures light scattered by individual particles carried in a sample air stream using a laser beam. According to current opinions, using a laser beam yields more accurate measurements than low-cost sensors using a light-emitting diode as a light source; however, further studies involving conducting extensive comparative tests seem necessary.

The gas sensors used by the station are as follows: Alphasense CO2 A4 (to measure carbon monoxide), Alphasense OX A431 (to measure ozone), and Alphasense NO2 A43F (to measure nitrogen dioxide).

The sensor contains an integrated fan to ensure a constant flow of air through a scattering chamber, which allows precise measurement of the number of particles in the air volume. It is also important that a number of calibration and validation procedures have already been carried out by the manufacturer.

Air pollution measurements were conducted during the period between 18 December 2017 and 9 March 2018 with the use of a testing station manufactured by the Sensonar company (station model: SensonarAirSense Extended, date of manufacture: 26 February 2017, calibration in zero chamber conducted on 7 March 2017, station software: SenseOS v.2.0). The station is a universal platform featured in measuring devices, such as medium-cost sensors, that performs real-time measurements of the following types of pollution: the level of particulate matter concentration in the atmosphere, PM2.5, PM10, PM1 in particular, and carbon monoxide $(\mathrm{CO})$, ozone $\left(\mathrm{O}_{3}\right)$, nitrogen dioxide $\left(\mathrm{NO}_{2}\right)$, and sulfur dioxide $\left(\mathrm{SO}_{2}\right)$.

Apart from pollution levels, the sensors also provide information about outside temperature, measuring time to an accuracy of one second, and identify the precise position (latitude and longitude) of the station, which is possible thanks to an embedded GPS sensor. It should be noted that the basic station itself is small in size (around $180 \times 130 \times 90 \mathrm{~mm}$ ), weighs around $1.2 \mathrm{~kg}$, can be easily transported from one place to another, and is powered by a simple mains plug via the urban power network $230 \mathrm{~V} / 50 \mathrm{~Hz}$. All of these factors allow the transmission of acquired measurements via a GSM network (modem LTE/3G), which guarantees reliable wireless transmission. The designed work temperature is from -15 to $+40{ }^{\circ} \mathrm{C}$, and the index protection of the station housing is IP63.

The measurement method of the physical parameters of particulate matter in atmospheric air is based on using the optical particle controller OPC $\mathrm{N}_{2}$ as an air sampler produced by the Alphasense company. It draws in the air from its surroundings, keeping a constant flow speed, and uses the method of laser light diffraction on physical particles. The average measurement error of particle sizes, based 
on their size, is presented in Figure 2. It also shows correlations with Grimm (GRIMM Aerosol Technik Ainring GmbH \& Co. KG, https: / www.grimm-aerosol.com) and TSI (TSI Incorporated, Shoreview, MN, USA, https:/ / www.tsi.com) devices. The measurement method of chemical parameters included in the atmospheric air is based on electrochemical gas sensors that react with a given compound via an ion-selective electrode of gas. The station carries out a real-time measurement within one second and an average measurement within three minutes. The measurement data is sent and stored in a database in real time. It is possible to access both interim and average pieces of data from any time window, from the moment that the station begins to operate until the present moment. The real-time measurement enables the generation of a warning and sends it to the visualisation system. The station was calibrated by the station manufacturer with the utmost care before the measurement period. Station sensors were calibrated in the zero chamber by determining their rest parameters, which is possible thanks to the ongoing exposure of the sensor to a mixture of gases similar to atmospheric air and deprived of the measured substances. The zero chamber was isolated from its surroundings and filled with synthetic air of a well-known composition and temperature. The test conditions were as follows: ambient temperature: $-19{ }^{\circ} \mathrm{C} \pm 2{ }^{\circ} \mathrm{C}$, sensor temperature: $23{ }^{\circ} \mathrm{C} \pm 2{ }^{\circ} \mathrm{C}$, measurement duration: $7 \mathrm{~h} 30 \mathrm{~min}$, synthetic air of purity N 5.0/99.999\%.

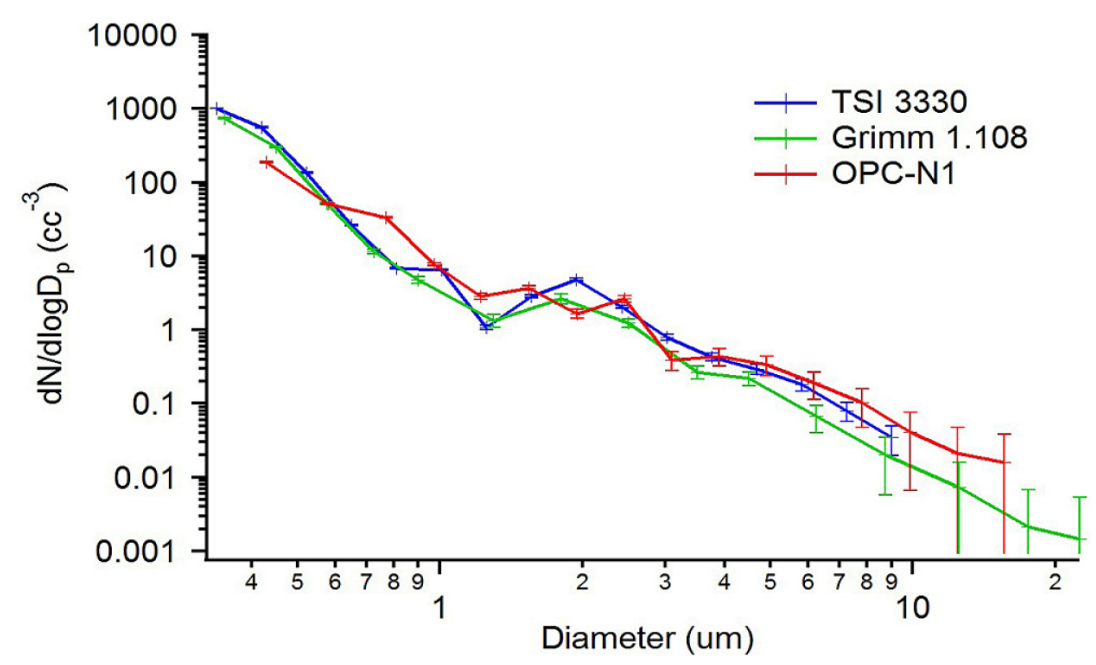

Figure 2. Average measurement error of particle sizes [21].

Alphasense sensors possess a certificate of compliance with the BS EN ISO 9001:2015 standard related to design, manufacture, sale, and distribution of gas, chemical, and physical sensors for industrial and administrative purposes. AirSense stations meet all of the requirements of an international ISO 37120:2014E standard regarding pollution levels in cities. The station is equipped with a GPS module, which allows every measurement to be automatically assigned a location on the map. It also enables the visualisation of moving objects, for example, public transport, drones, etc. The mobile deck can also serve as a model device for stationary equipment. Sending data from the station is carried out using the widely available LTE/3G mobile telephony network.

\subsection{Analysed Contaminants}

The following contaminants were investigated in the ambient air: particulate matter PM2.5, PM10, PM1, carbon monoxide $(\mathrm{CO})$, ozone $\left(\mathrm{O}_{3}\right)$, and nitrogen dioxide $\left(\mathrm{NO}_{2}\right)$. Sulphur dioxide $\left(\mathrm{SO}_{2}\right)$ values were not determined as the detector did not record measurable values during measurements. The analyses were conducted constantly, and the device exported the results of the analyses every hour of the day. It is worth mentioning that the analysed air contaminants were determined automatically, which means that they did not require sampling and transporting to the laboratory for further analytic procedures. 


\subsection{Air Quality Standards}

To determine the quality of the air in the investigated area, the measurements of the analysed air pollutants were compared with Polish permissible levels of selected pollutants in the air [22], the European Union reference values [23], and World Health Organization (WHO) air quality guidelines (AQGs) [24]. Such permissible concentrations are set to protect human health, meaning that adverse health effects are not likely to be observed when measurements are below these values. Moreover, to confirm the reliability of the tested sensors, the achieved results of measurements were compared with the results of the air pollution measurements obtained under the regional monitoring system conducted by the Chief Inspectorate of Environmental Protection in Poland [13].

\subsection{Air Quality Index}

In order to present the measured results of atmospheric air quality, the study uses the European Common Air Quality Index (CAQI), which describes the main air pollutants (called core pollutants in the methodology), such as $\mathrm{PM} 10, \mathrm{NO}_{2}, \mathrm{O}_{3}$, and if there is access to relevant data, also takes into consideration other pollutants (called auxiliary) as follows: $\mathrm{CO}, \mathrm{PM} 2.5$, and $\mathrm{SO}_{2}$. The values of the CAQI were calculated following CITEAIR Project guidelines [25]. The methodology for general background air quality in the city, as it describes the exposure of an average citizen, was used in

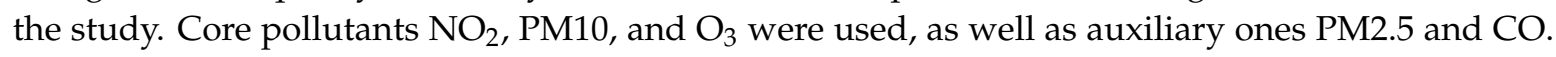
This index was chosen because it is recognisable for the comparison of air quality among different cities in Europe, in this case tourist cities, and so far, the regional monitoring system in Poland has not included smaller towns in the country.

\section{Results and Discussion}

\subsection{Concentrations of Pollutants in Ambient Air}

The results of the measurements of six air pollutants in the Niedzica recreational area are presented in Table 2. It can be seen that the measurements made with Alphasense sensors are comparable to the values achieved under the regional monitoring system of the Chief Inspectorate of Environmental Protection in Poland. The measurements revealed that in December 2017 and January 2018, the highest pollution concentrations were found on weekends and holidays. In the second half of January, in February and March, this trend continued, but also exceeded the admissible values during the remaining days of the week. It may be related to the fact that tourists account for a significant population increase in these towns on the weekends and during winter holidays.

It should also be noted that residents of the analysed communities stay at home more often and for longer during this period, as children do not attend school then; this may suggest that the most important factors affecting the air quality in the studied area includes the combustion of poor quality fuels in furnaces (including coal silt, coal flotation concentrate, and coal). In all analysed locations, the impact of pollution from the operation of vehicles driving on the local roads should also be taken into account; e.g., in the analysis of Klikuszowa, the significant impact of traffic pollution along the national road DK 47 should be taken into account. 
Table 2. Mean $24 \mathrm{~h}$ concentrations (unless stated differently) of analysed contaminants in ambient air (nd-not determined; ${ }^{*}$ only $24 \mathrm{~h}$ and $8 \mathrm{~h}$ permissible levels or guidelines were analysed; -: not applicable to $24 \mathrm{~h}$ or $8 \mathrm{~h}$ averaging periods; WHO AQGs-World Health Organization air quality guidelines).

\begin{tabular}{|c|c|c|c|c|c|c|c|c|c|}
\hline \multirow{2}{*}{ Location } & \multirow{2}{*}{ Location Number } & $\mathrm{CO}$ & $\mathrm{CO}_{8 \mathrm{~h}}$ & $\mathrm{O}_{3}$ & $\mathrm{O}_{38 \mathrm{~h}}$ & $\mathrm{NO}_{2}$ & PM10 & PM2.5 & PM1 \\
\hline & & \multicolumn{8}{|c|}{$\mu \mathrm{g} / \mathrm{m}^{3}$} \\
\hline Maniowy & 1 & 358 & 315 & 97.1 & 48.7 & 68.7 & 120 & 37.7 & 29.4 \\
\hline Łapsze Wyżne & 2 & 577 & 339 & 89.2 & 45.7 & 70.2 & 48.7 & 37.9 & 30.7 \\
\hline Frydman & 3 & 325 & 270 & 94.6 & 48.8 & 69.7 & 28.0 & 27.4 & 23.3 \\
\hline Klikuszowa & 4 & 225 & 186 & 112 & 56.2 & 87.4 & 20.3 & 19.8 & 17.1 \\
\hline Jurgów & 5 & 584 & 377 & 99.9 & 47.4 & 92.1 & 32.0 & 31.5 & 26.6 \\
\hline Huba & 6 & 352 & 258 & 106 & 55.9 & 71.5 & 138 & 55.3 & 41.6 \\
\hline Ludźmierz & 7 & 344 & 349 & 85.6 & 42.2 & 65.5 & 58.1 & 43.5 & 35.6 \\
\hline Kacwin & 8 & 518 & 419 & 85.1 & 42.5 & 88.9 & 63.9 & 63.3 & 52.5 \\
\hline Dębno & 9 & 647 & 531 & 78.0 & 39.8 & 109 & 107 & 95.2 & 80.2 \\
\hline Czorsztyn & 10 & 264 & 225 & 109 & 54 & 129 & 31.0 & 29.4 & 25.1 \\
\hline Niedzica & 11 & 574 & 513 & 98.9 & 49.5 & 141 & 60.4 & 59.4 & 50.9 \\
\hline Waksmund & 12 & 598 & 561 & 95.5 & 46.3 & 71.5 & 68.8 & 64.3 & 53.3 \\
\hline study area & & 447 & 362 & 96.0 & 48.1 & 88.7 & 65.0 & 47.1 & 38.9 \\
\hline $\begin{array}{l}\text { Regional monitoring } \\
\text { system station in } \\
\text { Nowy Targ }\end{array}$ & $\mathrm{n} 1$ & nd & nd & nd & nd & nd & 90.1 & nd & nd \\
\hline $\begin{array}{l}\text { Regional monitoring } \\
\text { system station in } \\
\text { Zakopane }\end{array}$ & $\mathrm{n} 2$ & 887 & 1474 & 40.6 & 59.4 & 32.4 & 51.9 & nd & nd \\
\hline \multicolumn{10}{|l|}{ Averaging period * } \\
\hline $\begin{array}{l}\text { Permissible level } \\
\text { Poland [22] }\end{array}$ & & 10,000 & - & - & 120 & - & 50 & - & - \\
\hline EU guideline [24] & & 10,000 & - & - & 120 & - & 50 & - & - \\
\hline WHO AQGs [24] & & - & - & - & 100 & - & 50 & 25 & - \\
\hline
\end{tabular}

\subsection{Air Quality Standards}

According to permissible values of pollutants in the air [22] and EU and WHO [23] guidelines (Table 2), it can be stated that during the time of the study, the permissible $24 \mathrm{~h}$ concentration for PM10 $\left(50 \mu \mathrm{g} / \mathrm{m}^{3}\right)$ was exceeded in seven locations, in the following decreasing order:

Huba $>$ Maniowy $>$ Dębno $>$ Waksmund $>$ Kacwin $>$ Niedzica $>$ Ludźmierz.

Moreover, recommendations from the WHO $24 \mathrm{~h}$ quality guideline for PM2.5 $\left(25 \mu \mathrm{g} / \mathrm{m}^{3}\right)$ were exceeded in all 12 investigated locations. In addition, the mean concentration from the investigated area during the period between 18 December 2018 and 9 March $2019\left(65.0 \mu \mathrm{g} / \mathrm{m}^{3}\right)$ exceeded the permissible $24 \mathrm{~h}$ PM10 concentration. The mean concentration for other contaminants in the area did not exceed existing permissible concentrations, and these values were as follows ( $\mu \mathrm{g} / \mathrm{m}^{3}$ ): $\mathrm{CO} 447$, $\mathrm{CO}_{8 \mathrm{~h}}$ 362, $\mathrm{O}_{3}$ 96.0, $\mathrm{O}_{3} 8 \mathrm{~h} 48.1, \mathrm{NO}_{2}$ 88.7, PM2.5 47.1, and PM1 38.9. It can be observed that $\mathrm{CO}$ concentration was higher than other pollutants, which can be explained by the incomplete combustion of bad quality fuels and wastes for heating purposes. However, it needs to be emphasised that no other $24 \mathrm{~h}$ permissible or guideline concentrations were established for the investigated contaminants, which does not automatically mean that the air quality was good.

\subsection{Air Quality Index}

Taking the above into consideration, the results obtained in the study were used to define the European CAQI index, which allows for easy comparison of the air quality in different cities using colors from dark green (very low air pollution) to dark red (very high air pollution), see Table 3, and, as such, is valuable when comparing the air quality in tourist towns across Europe. The calculated 
values of the CAQI index, in Table 4, revealed that the highest pollution was caused by PM10 as a core pollutant and PM2.5 as an auxiliary pollutant. Generally, contamination was determined as high and very high with these two fractions of PM (PM1 is not determined in the CAQI index), generally describing pollution during the monitored period as high and very high. The results were correlated with low temperatures during winter days, which suggests that burning poor quality fuel and trash for heating purposes is the source of contamination. They also indicate that ecological awareness among inhabitants of small towns in Poland is too low.

Table 3. European Common Air Quality Index (CAQI) grid with index classes.

\begin{tabular}{|c|c|}
\hline European CAQI Grid & Index Class \\
\hline 0 to 25 & Very low \\
26 to 50 & Low \\
51 to 75 & Medium \\
76 to 100 & High \\
$>100$ & Very high \\
\hline
\end{tabular}


Table 4. Values of calculated European CAQI index of air quality in the analysed region of Niedzica, where "_" means not applicable.

\begin{tabular}{|c|c|c|c|c|c|c|c|c|c|}
\hline \multirow{2}{*}{ Location } & \multirow{2}{*}{ Place } & & \multicolumn{7}{|c|}{ Day of the Week } \\
\hline & & & Monday & Tuesday & Wednesday & Thursday & Friday & Saturday & Sunday \\
\hline \multirow{6}{*}{ Maniowy } & \multirow{6}{*}{ school } & Date & 18.12 .2017 & 19.12.2017 & 20.20 .2017 & 21.12 .2017 & 22.12 .2017 & 23.12 .2017 & 24.12 .2017 \\
\hline & & CAQI & 76 (PM2.5) & 53 (PM10) & 62 (PM2.5) & 62 (PM2.5) & 32 (PM2.5) & $27\left(\mathrm{O}_{3}\right)$ & $26\left(\mathrm{O}_{3}\right)$ \\
\hline & & Date & 25.12 .2017 & 26.12 .2017 & 27.12 .2017 & 28.12 .2017 & 29.12 .2017 & 30.12 .2017 & 31.12 .2017 \\
\hline & & CAQI & 91 (PM10) & $>100$ (PM10) & $>100$ (PM10) & 54 (PM2.5) & 84 (PM2.5) & $>100$ (PM2.5) & $>100($ PM10) \\
\hline & & Date & 01.01 .2018 & 02.01 .2018 & - & - & - & - & - \\
\hline & & CAQI & $>100$ (PM10) & $>100$ (PM10) & - & - & - & - & - \\
\hline \multirow{2}{*}{$\begin{array}{l}\text { Łapsze } \\
\text { Wyżne }\end{array}$} & \multirow{2}{*}{ school } & Date & - & - & 03.01 .2018 & 04.01 .2018 & 05.01 .2018 & 06.01 .2018 & 07.01 .2018 \\
\hline & & CAQI & - & - & 85 (PM2.5) & 63 (PM2.5) & 76 (PM2.5) & $>100$ (PM2.5) & 75 (PM2.5) \\
\hline \multirow{2}{*}{ Frydman } & \multirow[b]{2}{*}{ school } & Date & 08.01 .2018 & 09.01 .2018 & 10.01 .2018 & 11.01 .2018 & 12.01 .2018 & 13.01 .2018 & 14.01.2018 \\
\hline & & CAQI & 81 (PM2.5) & 33 (PM10) & 31 (PM10) & 76 (PM10) & 62 (PM2.5) & 31 (PM10) & 32 (PM10) \\
\hline \multirow{2}{*}{$\begin{array}{l}\text { Kilku- } \\
\text { szowa }\end{array}$} & \multirow{2}{*}{ school } & Date & 15.01 .2018 & 16.01 .2018 & 17.01 .2018 & 18.01 .2018 & 19.01 .2018 & - & - \\
\hline & & CAQI & 79 (PM10) & 54 (PM2.5) & 21 (PM10) & $27\left(\mathrm{O}_{3}\right)$ & $29\left(\mathrm{O}_{3}\right)$ & - & - \\
\hline \multirow{4}{*}{ Jurgów } & \multirow{4}{*}{ comparative area } & Date & - & - & $\frac{-1(1+1+0)}{-}$ & - & - & 20.01 .2018 & 21.01 .2018 \\
\hline & & CAQI & - & - & - & - & - & 85 (PM2.5) & 63 (PM2.5) \\
\hline & & Date & 22.01 .2018 & - & - & - & - & - & - \\
\hline & & CAQI & 84 (PM2.5) & - & - & - & - & - & - \\
\hline \multirow{2}{*}{ Huba } & \multirow{2}{*}{ fire station } & Date & - & 23.01 .2018 & 24.01 .2018 & 25.01 .2018 & 26.01 .2018 & 27.01 .2018 & 28.01 .2018 \\
\hline & & CAQI & - & 100 (PM2.5) & 34 (PM10) & $27\left(\mathrm{O}_{3}\right)$ & 48 (PM2.5) & $>100$ (PM10) & $>100$ (PM10) \\
\hline \multirow{4}{*}{$\begin{array}{l}\text { Ludź- } \\
\text { mierz }\end{array}$} & \multirow{4}{*}{ school } & Date & - & - & 31.01 .2018 & 01.02 .2018 & 02.02 .2018 & 03.02 .2018 & 04.02 .2018 \\
\hline & & CAQI & - & - & 38 (PM2.5) & $>100(\mathrm{PM} 2.5)$ & 76 (PM10) & $>100$ (PM10) & 86 (PM2.5) \\
\hline & & Date & 05.02 .2018 & - & - & - & - & - & - \\
\hline & & CAQI & 31 (PM10) & - & - & - & - & - & - \\
\hline \multirow{2}{*}{ Kacwin } & \multirow{3}{*}{ school } & Date & - & 06.02 .2018 & 07.02 .2018 & 08.02 .2018 & 09.02 .2018 & 10.02 .2018 & 11.02 .2018 \\
\hline & & CAQI & - & 100 (PM2.5) & $>100$ (PM2.5) & 100 (PM2.5) & 86 (PM2.5) & 80 (PM10) & 85 (PM2.5) \\
\hline \multirow{4}{*}{ Dębno } & & Date & 12.02 .2018 & 13.02 .2018 & 14.02 .2018 & 15.02 .2018 & 16.02 .2018 & 17.02.2018. & 18.02 .2018 \\
\hline & \multirow{3}{*}{ school } & CAQI & $>100$ (PM10) & $>100$ (PM2.5) & 84 (PM2.5) & 78 (PM10) & $>100$ (PM10) & $>100$ (PM10) & 100 (PM2.5) \\
\hline & & Date & 19.02 .2018 & - & - & - & - & - & - \\
\hline & & CAQI & 77 (PM2.5) & - & - & - & - & - & _- \\
\hline \multirow{4}{*}{ Czorsztyn } & \multirow{4}{*}{ fire station } & Date & - & 20.02 .2018 & 21.02 .2018 & 22.02 .2018 & 23.02 .2018 & 24.02 .2018 & 25.02 .2018 \\
\hline & & CAQI & - & 94 (PM2.5) & 84 (PM2.5) & 61 (PM2.5) & 76 (PM2.5) & 34 (PM10) & 60 (PM2.5) \\
\hline & & Date & 26.02 .2018 & - & - & - & - & - & - \\
\hline & & CAQI & 62 (PM2.5) & - & - & - & - & - & - \\
\hline \multirow{4}{*}{ Niedzica } & \multirow{4}{*}{ school } & Date & - & 27.02 .2018 & 28.02 .2018 & 01.03 .2018 & 02.03 .2018 & 03.03 .2018 & 04.03 .2018 \\
\hline & & CAQI & - & 80 (PM2.5) & 85 (PM2.5) & $>100$ (PM2.5) & 79 (PM10) & $>100$ (PM2.5) & $>100$ (PM2.5) \\
\hline & & Date & 05.03 .2018 & - & - & - & - & - & - \\
\hline & & CAQI & 86 (PM2.5) & - & - & - & - & - & - \\
\hline $\begin{array}{l}\text { Waks- } \\
\text { mund }\end{array}$ & school & $\begin{array}{l}\text { Date } \\
\text { CAQI }\end{array}$ & $\begin{array}{l}- \\
-\end{array}$ & $\begin{array}{l}06.03 .2018 \\
82 \text { (PM2.5) }\end{array}$ & $\begin{array}{l}07.03 .2018 \\
76 \text { (PM10) }\end{array}$ & $\begin{array}{l}08.03 .2018 \\
>100 \text { (PM10) }\end{array}$ & $\begin{array}{r}09.03 .2018 \\
>100 \text { (PM2.5) }\end{array}$ & $\begin{array}{l}- \\
-\end{array}$ & - \\
\hline
\end{tabular}




\section{Conclusions}

It is worth noting that during the periods characterised by low temperatures, substance concentrations exceeded the admissible values in all studied locations. This suggests that the most important factors in determining the air quality in the studied area include the combustion of poor quality fuels in household furnaces for heating purposes (fireplaces, coal stoves, and kitchen stoves). The inventory of ground-level emission sources and operation of local heat energy in the analysed municipalities should be prepared. It is recommended that increased investment in energy-efficient heating devices, thermo-modernisation of buildings, and the possible use of alternative energy sources can significantly improve the current state of air. At the same time, it is advisable to constantly monitor the air quality and to eliminate the incineration of trash and fuels of poor quality. The main problem associated with low air quality is the inhalation of toxic substances during the heating season, which are carcinogenic, mutagenic compounds and decrease fertility. It is also proposed that the public be constantly educated in the field of air protection and the promotion of good practices, which can also have a good economic effect on households. Summing up, it should be stated that the ban on the combustion of poor quality fuels and the obligation to replace old heating devices, introduced in 2017, can significantly improve the air quality and thus increase the attractiveness of the analysed area for tourist and recreational purposes.

\section{The results obtained in the study allow the formulation of the following conclusions:}

- Air quality standards in the Niedzica recreational area (for existing $24 \mathrm{~h}$ and $8 \mathrm{~h}$ averaging periods) were exceeded in seven out of twelve locations in the case of PM10 and in all twelve locations in the case of PM2.5.

- The highest air pollution was recorded on non-working days. Heating during winter days was recognised as a major source of air contamination with different PM fractions.

- The European CAQI index demonstrated that PM10 and PM2.5 were primarily responsible for high values of air pollution during winter days, based on core pollutants in the background index.

- Due to the wide spectrum of measured parameters and the calibration and validation procedures carried out by the manufacturer, the application of medium-cost sensors seems to be a good alternative to both professional measurement stations and low-cost devices.

Author Contributions: Conceptualization, E.A., E.H.-R., M.K.-D., R.K., J.W.; Data curation, J.D., A.G.-K., D.P.; Formal analysis, J.W.; Funding aquisition, R.K.; Investigation, E.A., A.G.-K., R.K., J.W.; Methodology, E.A., A.G.-K., M.K.-D., R.K., J.W.; Project administration, R.K., J.W.; Resources, A.G.-K.; Software, J.D.; Supervision, M.K.-D., R.K., J.W.; Validation, E.H.-R., J.W.; Visualisation, R.K., D.P.; Writing - original draft, E.A., A.G.-K., E.H.-R., R.K., J.W.; Writing - review and editing, E.A., A.G.-K., E.H.-R., R.K., D.P., J.W.

Funding: This research received no external funding.

Acknowledgments: We would like to express our thanks to the "Energy Cluster of Czorsztyn Water Reservoir" and especially its representative, Marcin Skórnóg, as well as to the authorities of the local municipalities for their assistance in conducting our study on air pollution. We would like to thank Robert Steven for his proofreading.

Conflicts of Interest: The authors declare no conflict of interest.

\section{Abbreviations}

The following abbreviations are used in this manuscript:

$\begin{array}{ll}\text { CAQI } & \text { Common Air Quality Index } \\ \text { GBD } & \text { Global Burden of Disease } \\ \text { GPS } & \text { Global Positioning System } \\ \text { GSM } & \text { Global System for Mobile Communications } \\ \text { LTE/3G } & \text { Long-Term Evolution/3 Generation } \\ \text { OPC } & \text { Optical particle counter } \\ \text { WHO } & \text { World Health Organization }\end{array}$

NASA SRTM National Aeronautics and Space Administration Shuttle Radar Topography Mission 


\section{References}

1. OECD. The Economic Consequences of Outdoor Pollution; OECD Publishing: Paris, France, 2016.

2. European Parliament. Directive 2008/50/EC of the European Parliament and of the Council of 21 May 2008 on Ambient Air Quality and Cleaner Air for Europe. 2008. Available online: http:/ /news.cleartheair.org.hk/ wp-content/uploads/2013/02/LexUriServ.pdf (accessed on 26 May 2019).

3. Sobolewski, M. Air Protection in Poland/Ochrona Powietrza w Polsce; Biuro Analiz Sejmowych: Warszawa, Poland, 2016.

4. European Environment Agency. Air Quality in Europe-2013 Report; EEA Report No 9/2013; Publications Office of the European Union: Luxembourg, 2013.

5. Pope, C.A., III; Dockery, D.W. Health Effects of Fine Particulate Air Pollution: Lines that Connect. J. Air Waste Manag. Assoc. 2006, 56, 709-742. [CrossRef] [PubMed]

6. Perez, L.; Medina-Ramón, M.; Künzli, N.; Alastuey, A.; Pey, J.; Pérez, N.; Garcia, R.; Tobias, A.; Querol, X.; Sunyer, J. Size Fractionate Particulate Matter, Vehicle Traffic, and Case-Specific Daily Mortality in Barcelona, Spain. Environ. Sci. Technol. 2009, 43, 4707-4714. [CrossRef] [PubMed]

7. Qiu, H.; Yu, I.T.S.; Tian, L.; Wang, X.; Tse, L.A.; Tam, W.; Wong, T.W. Effects of Coarse Particulate Matter on Emergency Hospital Admissions for Respiratory Diseases: A Time-Series Analysis in Hong Kong. Environ. Health Perspect. 2012, 120, 572-576. [CrossRef] [PubMed]

8. Kelly, F.J.; Fussell, J.C. Linking ambient particulate matter pollution effects with oxidative biology and immune responses. Ann. N. Y. Acad. Sci. 2015, 1340, 84-94. [CrossRef] [PubMed]

9. Loeb, L.A. A Mutator Phenotype in Cancer. Cancer Res. 2001, 61, 3230-3239. Available online: http: / / cancerres.aacrjournals.org/content/61/8/3230.full.pdf (accessed on 26 May 2019). [PubMed]

10. Potgieter-Vermaak, S.; Rotondo, G.; Novakovic, V.; Rollins, S.; Van Grieken, R. Component-specific toxic concerns of the inhalable fraction of urban road dust. Environ. Geochem. Health 2012, 34, 689-696. [CrossRef] [PubMed]

11. World Health Organization. Health Effects of Particulate Matter: Policy Implications for Countries in Eastern Europe, Caucasus and Central Asia; World Health Organization (WHO) Regional Office for Europe: Copenhagen, Denmark, 2013.

12. Federal Council; Swiss Confederation. Environment Switzerland 2018, Report of the Federal Council, Swiss Confederation; No UI-1813-E; Federal Council: Bern, Switzerland, 2018.

13. Regional Inspectorate for Environmental Protection in Kraków, Poland. Available online: http://krakow. pios.gov.pl/ (accessed on 26 May 2019).

14. Gerboles, M.; Spinelle, L.; Borowiak, A. Measuring Air Pollution with Low-Cost Sensors. Thoughts on the Quality of Data Measured by Sensors; Joint Research Centre, EU Science Hub: Brussels, Belgium, 2017.

15. Williams, R.; Kilaru, V.; Snyder, E.; Kaufman, A.; Dye, T.; Rutter, A.; Russell, A.; Hafner, H. Air Sensor Guidebook; EPA/600/R-14/159 (NTIS PB2015-100610); U.S. Environmental Protection Agency: Washington, DC, USA, 2014.

16. Liu, D.; Zhang, Q.; Jiang, J.; Chen, D.R. Performance calibration of low-cost and portable particular matter (PM) sensors. J. Aerosol Sci. 2017, 112, 1-10. [CrossRef]

17. Yang, D.; Ye, C.; Wang, X.; Lu, D.; Xu, J.; Yang, H. Global distribution and evolvement of urbanization and PM2.5 (1998-2015). Atmos. Environ. 2018, 182, 171-178. [CrossRef]

18. Wang, L.; Fang, B.; Law, R. Effect of air quality in the place of origin on outbound tourism demand: Disposable income as a moderator. Tour. Manag. 2018, 68, 152-161. [CrossRef]

19. Bełcik, M.; Trusz-Zdybek, A.; Zaczyńska, E.; Czarny, A.; Piekarska, K. Genotoxic and cytotoxic properties of PM2.5 collected over the year in Wrocław (Poland). Sci. Total Environ. 2018, 637, 480-497. [CrossRef] [PubMed]

20. Dzikuć, M. Problems associated with the low emission limitation in Zielona Góra (Poland): Prospects and challenges. J. Clean. Prod. 2017, 166, 81-87. [CrossRef]

21. Alphasense Ltd, Sensor Technology House. Technical Specification for OPC-N2 Performance Data; Doc. ref. OPC-N2/APR15; Great Notley, UK, 2015. Available online: http:/ / www.bjsydz.com/data/Datasheet/OPCN2.pdf (accessed on 26 May 2019).

22. Minister of the Environment. Regulation of the Minister of the Environment Concerning the Levels of Certain Substances in the Air of 24 August 2012; Item 1031; Dziennik Ustaw: Warszawa, Poland, 2012. 
23. Annesi-Maesano, I. The air of Europe: Where are we going? Eur. Respir. Rev. 2017. [CrossRef] [PubMed]

24. European Environment Agency. Air Quality in Europe-2018 Report; EEA Report No 12/2018; Publications Office of the European Union: Luxembourg, 2018.

25. Van den Elshout S.; Bartelds, H.; Heich, H.; Léger, K. CAQI Air Quality Index. Comparing Urban Air Quality across Borders; European Union, European Regional Development Fund: Brussels, Belgium, 2012. 